Delft University of Technology

\title{
Effect of Engine Integration on a 4.6\%-Scale Flying-V Subsonic Transport
}

van Empelen, S.A.; Vos, Roelof

DOI

10.2514/6.2021-0939

Publication date

2021

Document Version

Final published version

Published in

AIAA Scitech 2021 Forum

\section{Citation (APA)}

van Empelen, S. A., \& Vos, R. (2021). Effect of Engine Integration on a 4.6\%-Scale Flying-V Subsonic Transport. In AIAA Scitech 2021 Forum: 11-15 \& 19-21 January 2021, Virtual Event [AIAA 2021-0939] American Institute of Aeronautics and Astronautics Inc. (AIAA). https://doi.org/10.2514/6.2021-0939

\section{Important note}

To cite this publication, please use the final published version (if applicable).

Please check the document version above.

\section{Copyright}

Other than for strictly personal use, it is not permitted to download, forward or distribute the text or part of it, without the consent of the author(s) and/or copyright holder(s), unless the work is under an open content license such as Creative Commons.

\section{Takedown policy}

Please contact us and provide details if you believe this document breaches copyrights.

We will remove access to the work immediately and investigate your claim. 


\title{
Effect of Engine Integration on a 4.6\%-Scale Flying-V Subsonic Transport
}

\author{
S.A. van Empelen* and R. $\operatorname{Vos}^{\dagger}$ \\ Delft University of Technology, Kluyverweg 1 2629HS, Delft, The Netherlands
}

\begin{abstract}
The installation and interference effects of an engine and nacelle to a $4.6 \%$-scale half model of a Flying-V subsonic transport airplane are presented. Wind tunnel tests are performed at $20 \mathrm{~m} / \mathrm{s}$ in an open jet facility while balance measurements are taken to record lift, drag and pitching moment. The results show significant interference effects between the wing and engine. Interference drag is observed over the full range of angles of attack above $5^{\circ}$, with a maximum of 60 drag counts $\left(16.5 \%\right.$ of isolated-wing drag) at an angle-of-attack of $10^{\circ}$. At incidence angles lower than $5^{\circ}$, the interference effect during engine operation reduces the drag by approximately 20 counts. At high thrust settings and incidence angles between $-5^{\circ}$ and $12.5^{\circ}$ the interference effects amplify the lift coefficient. The pitching moment coefficient shows a similar interference effect as the lift coefficient, showing a strong correlation between the two coefficients. The interference effects of thrust and nacelle on lift and pitching moment are of the same order of magnitude as the effect of superpositioning the contributions of the isolated engine and the wing. They can therefore not be neglected. However, further research is needed to study the interaction effects on the local pressure distribution as this could not be derived from the measurements presented in this study.
\end{abstract}

Nomenclature

\section{Latin Symbols}

$A_{i} \quad$ intake surface area $\left(\mathrm{m}^{2}\right)$

$b \quad$ wing span (m)

$C_{L} \quad$ lift coefficient (-)

$C_{D} \quad$ drag coefficient (-)

$C_{M} \quad$ pitching moment coefficient (-)

$C_{T} \quad$ Propeller thrust coefficient (-)

$D \quad$ drag (N) or diameter (m)

$g \quad$ gravitational acceleration $\left(\mathrm{m} / \mathrm{s}^{2}\right)$

$J \quad$ Advance ratio (-)

$l \quad$ reference length $(\mathrm{m})$

$L \quad \operatorname{lift}(\mathrm{N})$

$M \quad$ Mach number (-)

$n \quad$ rotational velocity (rev/s)

$S \quad$ wing surface area $\left(\mathrm{m}^{2}\right)$

$T \quad$ thrust (N)

$V \quad$ velocity $(\mathrm{m} / \mathrm{s})$ $\alpha \quad$ angle of attack (deg)

$\delta \quad$ Interference change (-)

$\Delta \quad$ Installation change (-)

$\rho \quad$ density $\left(\mathrm{kg} / \mathrm{m}^{3}\right)$

$\mu \quad$ dynamic viscosity $\left(\mathrm{Ns} / \mathrm{m}^{2}\right)$

\section{Subscripts}

Greek Symbols

$\infty \quad$ free-stream

w wake

\section{Acronyms}

AoA Angle of attack

E Engine thrust

$\mathrm{N} \quad$ Nacelle

S Strut

PS Propulsion system

SSFT Sub-scale flight testing

W Wing

\section{Introduction}

Nonrecurring costs of aircraft design are very high, which is one of the reasons to opt for proven design choices during early design stages. As a result, aircraft configurations have remained very similar since the introduction of the Boeing

\footnotetext{
*MSc student, Faculty of Aerospace Engineering

$\dagger$ Assistant Professor, Faculty of Aerospace Engineering, r.vos@tudelft.nl, AIAA Associate Fellow
} 
707, featuring the well-understood, high aspect-ratio, swept-back wing, horizontal and vertical tail and tubular fuselage. The historical improvement of cruise lift-to-drag ratio $M(L / D)_{\max }$ of jetliners shows a trend that is moving towards an asymptote.[1] Breaking this trend requires the introduction of a concept that is radically different from the tube and wing configuration.[2] A new take on the flying wing type of airplane configuration comes in the form of the Flying V. The concept of the Flying V was first introduced and studied by Benad at Technische Universitat Berlin in collaboration with Airbus [3]. The Flying V is a concept for long-haul flight that minimize the amount of non-lifting aircraft structure. It consists of two highly swept inner wings with an internal cabin, outer wings with lower sweep and two large winglets with integrated rudders for directional control (see Figure 1). The aerodynamic design of the concept was reevaluated and optimized for cruise conditions by Faggiano et al. [4], resulting in the shape of the Flying V configuration as considered in this paper.

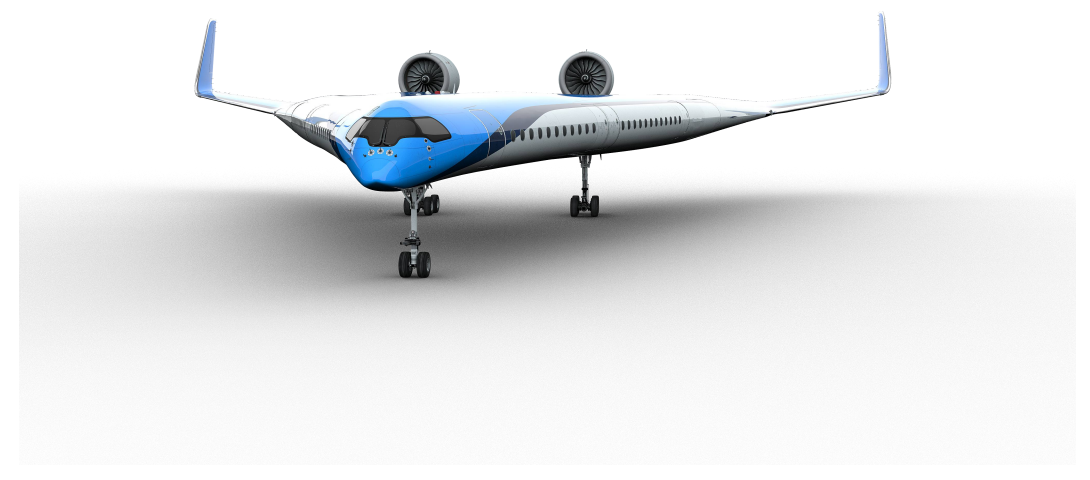

Fig. 1 Conceptual design of a Flying-V aircraft.

The costs of full scale testing are too high to be deemed a viable option for further research. Therefore, sub-scale flight testing (SSFT) is an attractive alternative to assess the configuration's performance in real flight conditions. Dynamic properties of an aircraft can be investigated at an affordable price in a wider range of conditions than a wind tunnel [5, 6]. An SSFT model of the Flying V is being finalized at TU Delft at the time of writing: However, before the SSFT model can take to the air, the flight characteristics of the design are to be tested numerically and in the wind tunnel. So far, numerical and experimental investigations have been performed to assess the performance, longitudinal static stability and control characteristics of the sub-scale model [4, 7, 8]. All of this research was either purely numerical or only involved the wing. The influence of engine integration on aircraft performance at this scale remains untested so far.

Assessing the installation effects of the engine on the airframe was performed by NASA and Boeing as part of the investigation into the blended wing body configuration. Their setup included multiple different configurations and measurement equipment, including through-flow nacelle (TFN) and powered testing, as described by Dickey et al. [9, 10] Most other facilities offering propulsion system integration testing use turbine powered simulators (TPS). Most of the TPS testing is aimed towards high speed integration effects. Most of these effects are compressibility and shock wave related and are not expected to show up at low-speed, high angle-of-attack flight. Major research institutions that published about engine integration studies done at their facilities include DLR [11, 12], the German-Dutch Wind Tunnels [13, 14], Aircraft Research Association (ARA) [15] and ONERA in France [16]. While the integration effects presented by these authors do not exactly match low speed testing effects, the thrust/drag accounting methods are very relevant as a reference for this work.

The bookkeeping method that allows a high accuracy in TPS testing revolves around isolated calibration of the engine. This calibration procedure allows nacelle flow correction coefficients to be determined, which are used to correct thrust in wing-on conditions. During wing-on testing, the nacelle is mounted directly to the wing. However, using internal measurements of pressure and total temperature, the engine thrust can accurately be determined based on isentropic flow calculations and the previously determined correction coefficients. This allows all the different acting forces to be specified, including a distinction between fan thrust, turbine thrust and inlet momentum. A schematic of such a thrust drag bookkeeping scheme is depicted in Figure 2, [12, 13, 15].

\footnotetext{
*The sub-scale flight test article has taken first flight in July of 2020. An abstract of this manuscript was prepared in May of 2020
} 


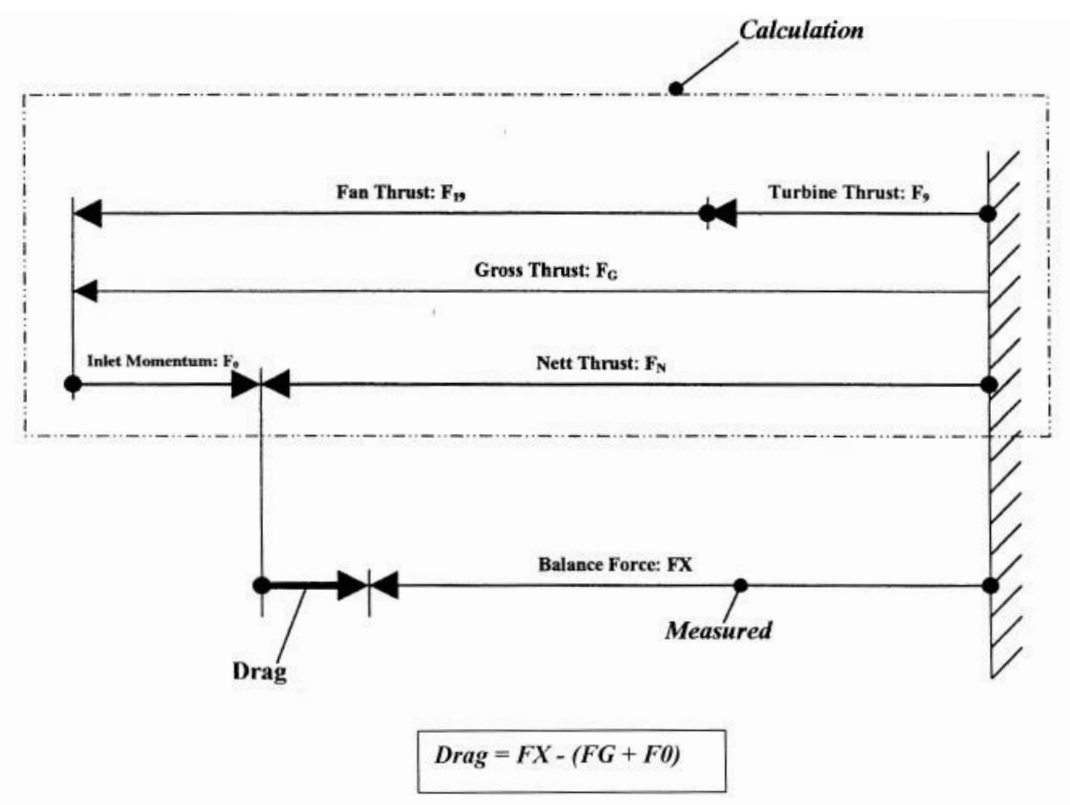

Fig. 2 Schematic of Thrust-Drag accounting for turbine powered wind tunnel testing [17]

General features of aerodynamic interference can then be split up into geometry effects and power effects, which can be measured separately. Both of them affect the flow around the aircraft. However they might be more easily understood when split up. Testing in TFN condition allows the pure geometry effects to be investigated and visualized before the addition of thrust.[13] The thrust dependent effects can be investigated using powered testing. The most obvious effect normally being the high velocity exhaust flow acting on the airframe. This effect is expected to be small, when taking into account the aft positioning of the Flying V engines. Nevertheless, the suction of the inlet flow might have a noticeable effect on the flow over the upper wing surface. Secondly, the induced flow velocities interact with the wing circulation, which, in the case of the Flying V, might increase at low flight velocities [11].

The integration of the engine with the airframe changes the local flow, changing the local flow conditions. In the numerical investigation done by Lv et al. [18], profile drag increased significantly under the influence of a closely coupled propulsion system at the rear end of a circular fuselage. The main source was an increase in pressure drag, but also due to increased friction drag. While this considered symmetric conditions, the Flying-V, with its engines mounted above and partially behind the wing, is expected not only to have a change in drag, but also a change in pitching moment and lift coefficient as a function of the engine thrust.

To assess the effect of the engine installation and the thrust on the aerodynamic characteristics of the Flying V, a wind tunnel test is performed. The goal of this paper is to present the findings of this investigation and show how the lift coefficient, pitching-moment coefficient and drag coefficient are affected by the thrust of the engine. The study is performed on a half model of the Flying-V wing at a scale of $4.6 \%$. This is the same scale as the flight-test article, which has the exact same geometry as the the wind tunnel model that is presented here. The results of this study are therefore important to understand how the longitudinal stability and trim properties change as a result of engine integration and throttle setting. This information can subsequently be utlized to select an appropriate center-of-gravity location for the SSFT test article.

The remainder of this paper has the following setup. In Section III the experimental setup of the wind-tunnel experiment is disclosed while Section III presents methodology that is used to account for the integration effects. In Section [IV] the results of the experiment is presented. First the experimental results of the isolated engine and nacelle are presented as well as the isolated wing. Then, the results of aircraft with integrated engine are presented. By applying the bookkeeping method, the interference effects are subsequently quantified. Conclusion and recommendations are presented in Section $\mathrm{V}$ 


\section{Experimental Setup}

Combining the experience gathered by Palermo [7], Viet [8]and Ruiz Garcia [19] on the testing of the half model Flying V, adding common practice of engine-integration testing, and taking into account the available resources at Delft University of Technology, results in the setup discussed in this section. First the wind tunnel is discussed, followed by a detailed description of the half model and the used measurement equipment and methods. A description of the wind tunnel tests and bookkeeping method is provided in Section III]

\section{A. Experimental Setup}

The experimental campaign is conducted in the Delft University of Technology Open Jet Facility (OJF). The OJF is a closed loop, low-speed wind tunnel with an octagonal test section of 2.85 by 2.85 meters and a maximum flow velocity of approximately $35 \mathrm{~m} / \mathrm{s}$. The airflow is driven by a large fan, powered by a $500 \mathrm{~kW}$ electric motor. To reduce velocity deviations and turbulence of the flow, the flow is forced through several dense wire meshes, before blowing into the test section through a contracting nozzle. Finally, any added heat is removed from the flow after the test section by a $350 \mathrm{~kW}$ radiator system, which keeps the flow at a constant temperature.[20]

The wind tunnel half model of the Flying V is a glass-fibre composite wing, with a semi span of $1.5 \mathrm{~m}$. The planform dimensions are provided in Figure 3 The wind tunnel model represents exactly half of the Flying V SSFT model, which is a $4.6 \%$ geometrically scaled model of the full scale design [7]. Zigzag strips are positioned at $5 \%$ chord to ensure a turbulent boundary layer flow over most of the wing surface.
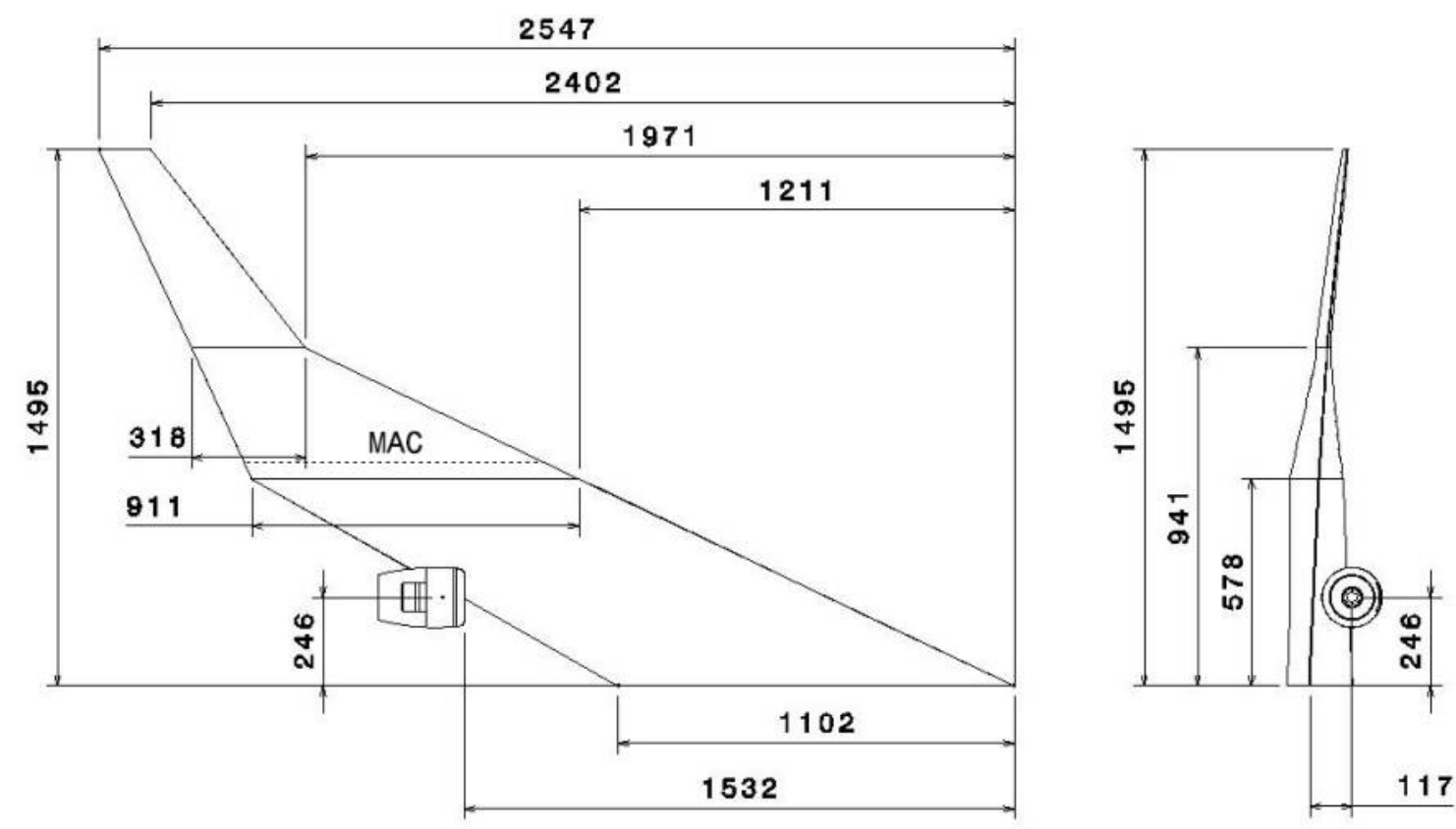

Fig. 3 Dimensions of the Flying $V$ half model, as previously used by Palermo, Viet and Ruiz Garcia. Now including engine position as proposed for the flight testing model. (Top view on the left, rear view on the right)

The nacelle has an axisymmetric design, with a slightly diverging inlet. The throat area $A_{i}$ is $0.010 \mathrm{~m}^{2}$, which diverges to the actuator disk surface area at the fan of $0.0113 \mathrm{~m}^{2}$ and then stays constant towards the outlet. A cross sectional view of the nacelle can be found in Figure 4 . The nacelle is constructed from a double layered carbon-fibre composite, to provide sufficient of stiffness to the structure.

The engine system selected for the SSFT Flying V are two electrically powered ducted fans designed for use on scale model aircraft (Schuebeler DS-86-AXI HDS ${ }^{\circledR}$ ). One of these electric fans is used during the wind tunnel campaign. It features 10 blades, a fan diameter of $120 \mathrm{~mm}$ and a fan swept area of $90 \mathrm{~cm}^{2}$. The fan is immediately followed by three 


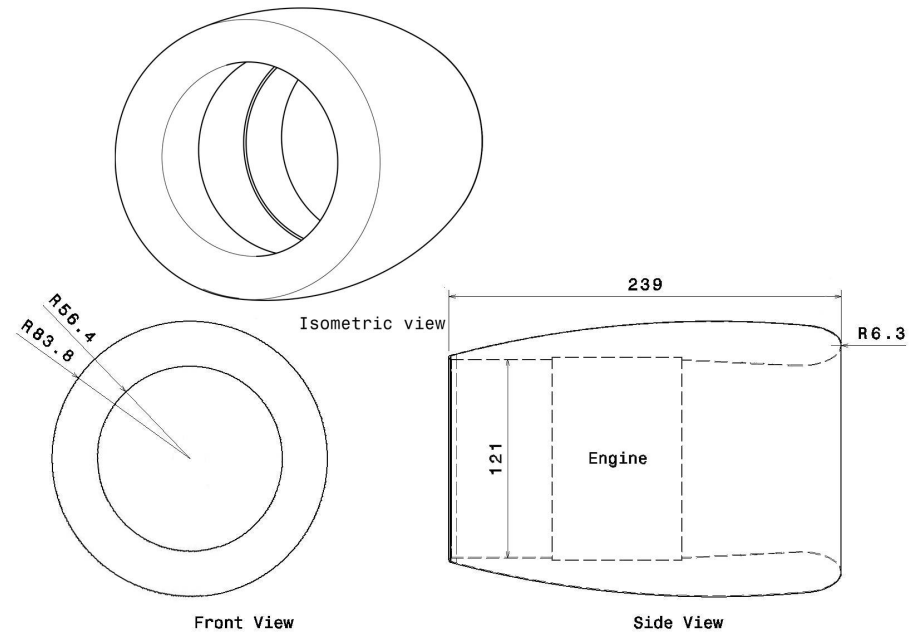

(a) Nacelle dimensions (mm)

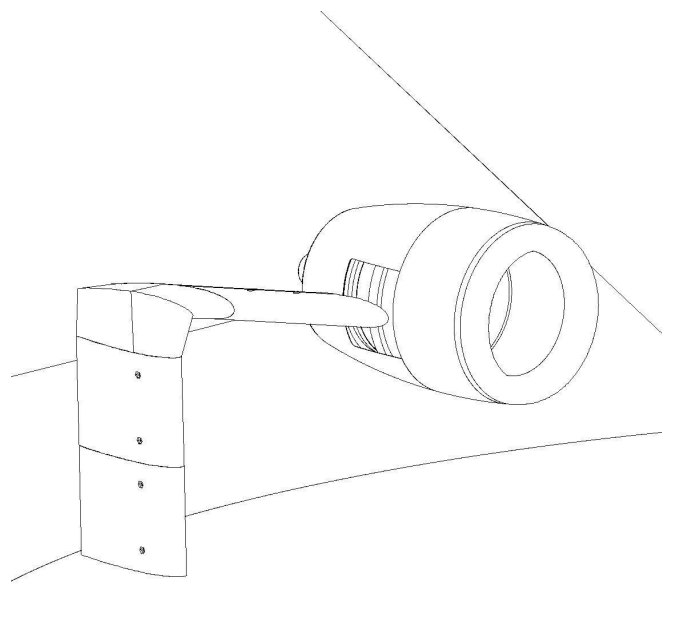

(b) Nacelle on engine strut

Fig. 4 Design of engine nacelle

stator vanes to reduce swirl of the exhaust flow. The engine specifications are presented in Table 1. A picture of the engine is shown in Fig. 5

Table 1 Engine Specifications

\begin{tabular}{ll}
\hline Fan diameter & $120 \mathrm{~mm}$ \\
Max. RPM & 33,500 \\
Design voltage & $44.4-50.4 \mathrm{~V}$ (12S LiPo) \\
Max current & $180 \mathrm{~A}$ \\
Max. Thrust & $86 \mathrm{~N}$ \\
Weight & $1190 \mathrm{~g}$ \\
Max. Motor Diameter & $56 \mathrm{~mm}$ \\
\hline
\end{tabular}

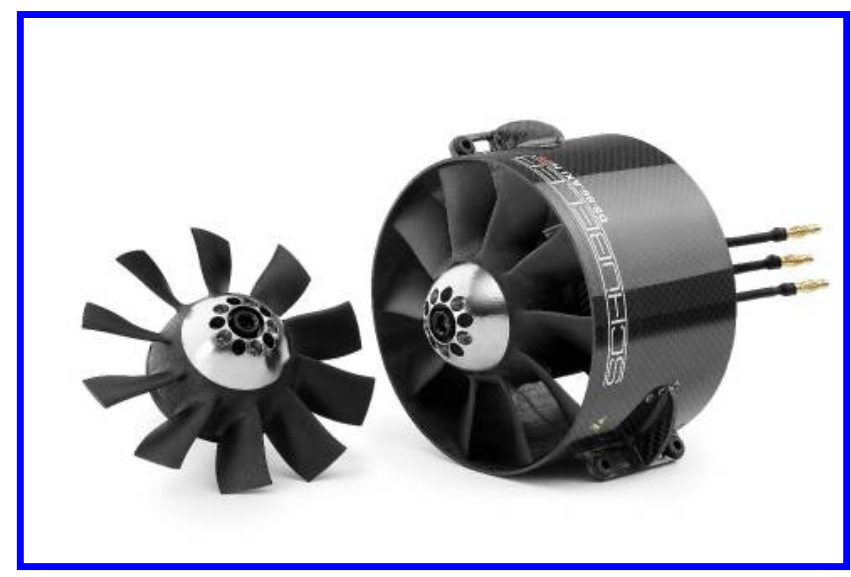

Fig. 5 Picture of the electric fan used in the wind tunnel campaign

The fan speed of the engine is controlled by an electronic speed controller (ESC). The specific type is a TMM 
25063-3, developed by MGM controllers. It controls the speed of the motor through the switching frequency of the three-phase power signal. While the motor does not measure its rotational speed, this is estimated through the back emf of the spinning motor. This value is logged by the ESC and stored on internal flash memory. Although the logged rotational velocity was verified with a stroboscope, it still provides an unquantified source of uncertainty. The thrust setpoint of the ESC is set through a pulse-width modulated signal from an Arduino Uno. DC power is supplied through a power supply of type TDK-Lambda GEN-60-85-3P400, capable of providing a maximum current of $85 \mathrm{~A}$ at $60 \mathrm{~V}$. Its control is set to provide a constant voltage of $50 \mathrm{~V}$. The maximum thrust setpoint is limited by the power that can be supplied by the power supply.

For this campaign is is decided to mount the engine on a support strut and connect it to the main supporting elements under the reflection plane. The engine is not mounted directly to the wing to allow for multiple engine positions to be tested. The engine support strut consists of a steel beam structure, with a 3D printed aerodynamic fairing. The fairing is based on the symmetric NACA 0012 profile, with a hollow leading edge to pass phase cables to power the engine, and a hollow trailing edge to house the pressure tubing for rake measurements. These are passed from the nacelle, through the fairing, to a location below the reflection plane, where the ESC and pressure transducers are situated. The engine mount in this setup connects to the "top" surface of the nacelle, as far away and downstream from the wing as possible, to minimize upstream interference effects. Figure $4(\mathrm{~b})$ shows a drawing of the engine and strut next to the wing.

A side and rear view of the complete wind tunnel setup is shown in 6 . Note that a preliminary center-of-gravity (CG) position is indicated, which acts as the moment reference point for the pitching moment coefficients. In Figure:7(a) and $7(\mathrm{~b})$ an isometric view and a picture of the setup are shown, respectively. All the aforementioned components are indicated clearly shown. A six axis strain gauge balance is mounted on a turn table, which is bolted to the base support table. Forces are transferred from the wing and engine to the balance through a stiff aluminium beam structure. The splitting plane is positioned flush with the nozzle mouth to protect the balance reading from further airflow. The reflection plane is positioned in clean air to provide it with a fresh boundary layer. Notice the large aerodynamic shield required to protect the wing and engine mounting structure from the airflow between the reflection plane and the splitting plane, while allowing rotation of the setup. Reference values of the setup are provided in the Table 2 The $X$-locations in that table refer to the leading-edge apex of wing at the reflection plane. The $Y$-location of the balance is assumed to coincide with the $Y$-location of the CG.

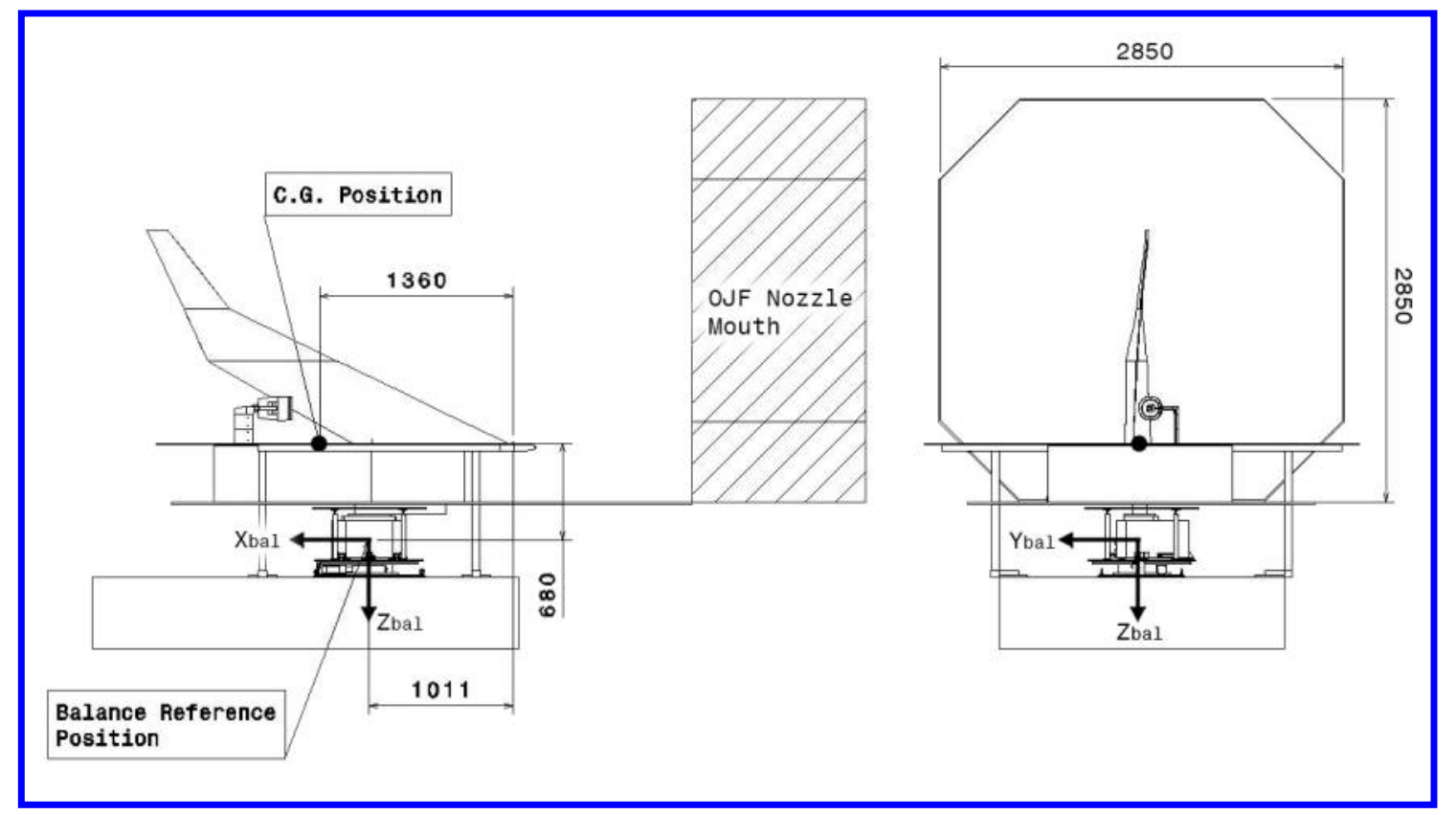

Fig. 6 Side view (left) and rear view (right) of the wind tunnel setup 


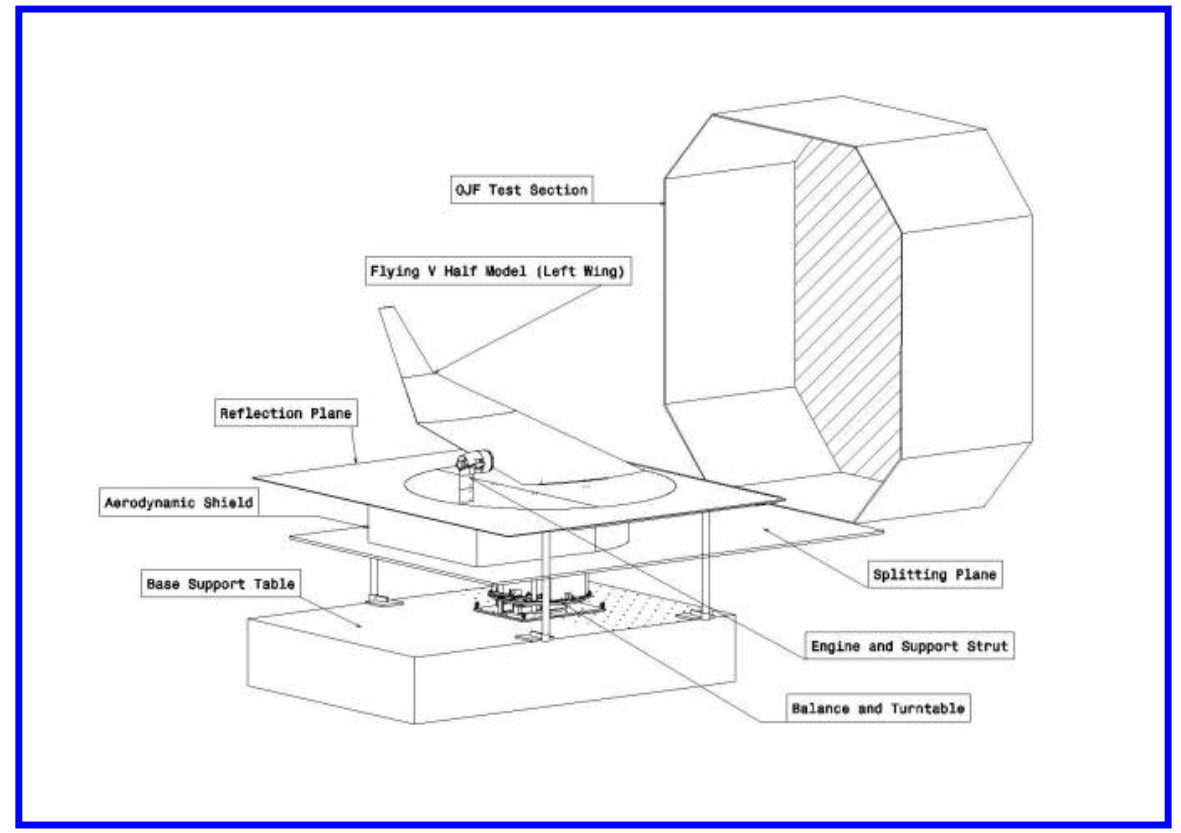

(a) Main components

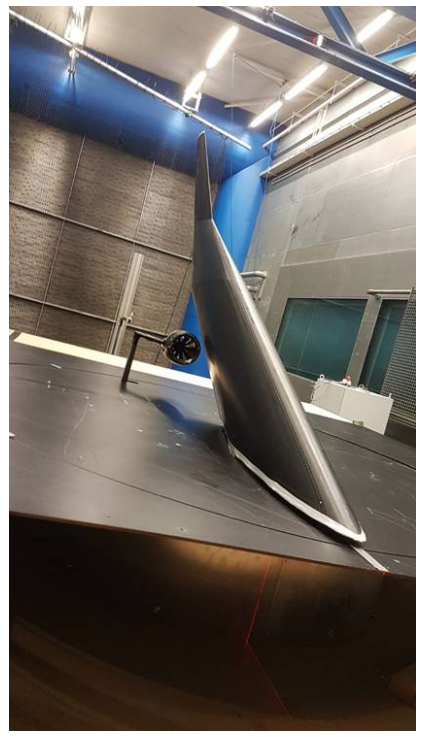

(b) Picture of setup

Fig. 7 Overview of experimental setup.

Table 2 Setup Reference Values

\begin{tabular}{lll}
\hline Wing surface Area & $\mathrm{S}$ & $0.935 \mathrm{~m}^{2}$ \\
Mean Aerodynamic Chord & $\bar{c}$ & $0.820 \mathrm{~m}$ \\
Center of gravity X location & $X_{\mathrm{CG}}$ & $1.360 \mathrm{~m}$ \\
Balance X location & $X_{\text {bal }}$ & $1.011 \mathrm{~m}$ \\
\hline
\end{tabular}

\section{Experimental Approach and Analysis}

To quantify the aerodynamic interaction between engine and airframe, a four-step approach is taken: 1) isolated engine calibration, 2) isolated wing tests, 3) integrated through-flow-nacelle tests and finally, 4) integrated engine tests in power-on conditions. The data of these tests is subsequently combined to assess the installation and interference effects. This is further detailed in the subsections below.

\section{A. Experimental approach}

The test matrix for the experiment is heavily based on the previously recorded behavior of the Flying $\mathrm{V}$ half model. Research done by Palermo [7], Viet [8] and Ruiz Garcia [19] provided the clean-wing trimmable angle-of-attack (AoA) range and optimal CG at $20 \mathrm{~m} / \mathrm{s}$ freestream velocity. The trimmable flight angle-of-attack range of the wing at $20 \mathrm{~m} / \mathrm{s}$ is limited due to a pitch break at $20^{\circ}$ AoA [7]. The optimal CG position defined from the spline model representation by Ruiz Garcia (1.360m from the nose of the aircraft) is used for all moment coefficient plots in this work. Therefore, in this study the measurement are taken over an angle-of-attack range between -5 and 30 degrees.

From Ruiz Garcia [19] it can be concluded that force coefficients are relatively independent of the airspeed. It is therefore decided to limit the size of the test matrix by testing only at two free-stream velocities. The choice is made to use a tunnel speed of $20 \mathrm{~m} / \mathrm{s}$ for all the main measurements of the campaign, since this is close to the intended take-off and landing velocity of the SSFT model. Unfortunately, testing the complete angle of attack range at higher Reynolds numbers is not possible. Balance load limits are reached when the velocity is increased beyond $20 \mathrm{~m} / \mathrm{s}$ and angles of attack reach 30 degrees. Therefore, measurements at $15 \mathrm{~m} / \mathrm{s}$ wind-tunnel speed are used to validate the results at selected data points.

The first step the test campaign is to calibrate the engine. To be able to separate effects as much as possible, the 
calibration is split into three steps.First the support on which the isolated engine is mounted is tested to quantify its contribution to lift, drag and pitching moment. The engine is easily disassembled from the nacelle to obtain a through-flow nacelle (TFN). This TFN is tested for the trimmable flight range $\left(-5^{\circ}\right.$ to $30^{\circ}$ with $2.5^{\circ}$ step) to measure its lift and drag contributions. These tests are subsequently repeated with the fan installed and at a range of thrust setpoints to investigate thrust effects on the isolated engine. Thrust is controlled through the pulse-width modulated duty cycle of the signal going to the electronic speed controller (ESC). A range of from idle to maximum thrust is used: $20 \%$ Duty cycle to $70 \%$ Duty cycle, with a step size of $5 \%$. The resolution of the angle of attack range, however, is reduced to $5^{\circ}$ to limit the overall amount of testing time.

With engine calibration done, the wing half model tests are performed to repeat part of the work done by Palermo [7], Viet [8] and Ruiz Garcia [19] for verification and validation purposes. It is hypothesized that the modified setup still leads to similar balance results. No control surface deflections are included in the test. The control surfaces are assumed to be far enough outboard not to influence the inboard flow field, allowing their effects to be superimposed to the results obtained from these tests. Experiments are performed ranging from -5 to +30 degrees angle of attack, with a step size of 2.5 degrees. This provides a good baseline polar for the isolated wing, while providing additional information around the pitch break compared to the previous studies.

In the next step, the TFN is integrated with the half model. These tests follow to quantify the installation and interference effects of the nacelle. The same range of angles-of-attack is used for this test as for that of the isolated wing. Tests with the wing and engine in power-on conditions are finally used to quantify the thrust effects of the integration. Here, the step size in angle-of-attack is increased to $5^{\circ}$ to reduce the overall testing time.

\section{B. Bookkeeping Method}

To properly account for the installation and interference effects, a bookkeeping method is applied to the balance measurements of the various tests. The bookkeeping definitions that are used in this method are repeated throughout the remainder of this work. The letters used in the equations in this section each represent a component, the definitions of the letters are summarized in Table 3. Letter combinations denote a measurement condition. For example, WENS is a measurement result including the wing, engine in power on conditions and the engine strut, while WNS defines the results obtained from the wing, nacelle and strut in TFN conditions. Following this definition, WEN is the notation of the aircraft in power-on conditions.

Table 3 Bookkeeping Nomenclature

\begin{tabular}{ll}
\hline $\mathrm{W}$ & Wing \\
$\mathrm{N}$ & Nacelle \\
$\mathrm{S}$ & Engine Strut \\
$\mathrm{E}$ & Engine thrust \\
$\mathrm{PS}$ & Propulsion system \\
\hline
\end{tabular}

As a first bookkeeping step, the engine strut that is included in the setup has to be subtracted from any measurement to obtain the forces acting on the aircraft only. The forces and moments acting on the strut are subtracted from measurements taken on the isolated nacelle and engine. This is done for both idle and power-on conditions to arrive at the forces and moments acting on the isolated nacelle $(\mathrm{N})$ and engine + nacelle $(\mathrm{EN})$, respectively:

$$
\begin{aligned}
\mathrm{N} & =\mathrm{NS}-\mathrm{S} \\
\mathrm{EN} & =\mathrm{ENS}-\mathrm{S}
\end{aligned}
$$

As an example, let us consider the estimation of the engine thrust. Subtracting the drag measurements of the nacelle and strut from the trust measurements in power-on conditions, provides an estimation for the generated engine thrust generated $\left(T_{\mathrm{E}}\right)$.

$$
T_{\mathrm{E}}=T_{\mathrm{ENS}}-D_{\mathrm{NS}}
$$

In this way, the drag of the nacelle, including any added internal drag in power-on conditions, is directly accounted for as a loss of thrust. According to the common definition of propeller thrust coefficient $C_{T}$, the thrust of a (ducted) 
propeller or fan is proportional to the fourth power of the disk diameter $(D)$ and the square of the rotational velocity $(n)$. [21] In other words, the thrust is proportional to the advance ratio $J$ as described the following equations:

$$
\begin{aligned}
C_{T} & =\frac{T_{\mathrm{E}}}{\rho n^{2} D^{4}} \\
J & =\frac{V_{\infty}}{n D}
\end{aligned}
$$

where $T_{\mathrm{E}}$ is the engine thrust and $\rho$ is the density.

Next, something similar can be done for the strut in wing-on conditions. In the following definitions, it is assumed that the downstream effects of the wing on the strut are much larger than the upstream effect of the strut on the wing. This allows the forces of the engine strut under influence of the pressure field of the wing, i.e. $S_{\mathrm{w}}$, to be taken as:

$$
\mathrm{S}_{\mathrm{w}}=\mathrm{WS}-\mathrm{W}
$$

Then, these newly defined forces acting on the engine strut are subtracted from the wing-on measurements of TFN and engine in the following way:

$$
\begin{gathered}
\mathrm{WN}=\mathrm{WNS}-\mathrm{S}_{\mathrm{w}}=\mathrm{WNS}-(\mathrm{WS}-\mathrm{W}) \\
\mathrm{WEN}=\mathrm{WENS}-\mathrm{S}_{\mathrm{w}}=\mathrm{WENS}-(\mathrm{WS}-\mathrm{W})
\end{gathered}
$$

This results in the forces and moments acting on the Wing+TFN and Wing+Engine combinations, respectively.

By combining the previously determined definitions, it is possible to obtain the installation and interference effects of the wing, nacelle and inlet steam tube. The latter is a function of the engine thrust. In this work, the changes in forces due to installation are denoted with the symbol $\Delta$. The installation effect of a propulsion system is defined as the force measurements of wing and engine, minus the force measurements of the isolated wing. It can be subdivided into the installation effect of the nacelle $\left(\Delta_{\mathrm{N}}\right)$ :

$$
\Delta_{\mathrm{N}}=\mathrm{WN}-\mathrm{W}
$$

and the installation of engine thrust $\left(\Delta_{\mathrm{E}}\right)$ :

$$
\Delta_{\mathrm{E}}=\mathrm{WEN}-\mathrm{WN}
$$

Together they form the total installation effect of the propulsion system $\left(\Delta_{\mathrm{PS}}\right)$ :

$$
\Delta_{\mathrm{PS}}=\mathrm{WEN}-\mathrm{W}=\Delta_{\mathrm{N}}+\Delta_{\mathrm{E}}
$$

The interference effects of a nacelle or propulsion system are defined as the difference between the installed system and the measurements of the isolated components. The interference effects are denote with the symbol $\delta$. The total interference effect can be subdivided into the interference effect of the nacelle $\left(\delta_{\mathrm{N}}\right)$ :

$$
\delta_{\mathrm{N}}=\mathrm{WN}-(\mathrm{W}+\mathrm{N})
$$

and the interference effect of the inlet streamtube through the engine thrust $\left(\delta_{\mathrm{E}}\right)$ :

$$
\delta_{\mathrm{E}}=(\mathrm{WEN}-\mathrm{WN})-(\mathrm{EN}-\mathrm{N})
$$

Addition of these terms results in the interference effect of the propulsion system $\left(\delta_{\mathrm{PS}}\right)$ [17]:

$$
\delta_{\mathrm{PS}}=\mathrm{WEN}-(\mathrm{W}+\mathrm{EN})
$$

\section{Results}

\section{A. Isolated Engine Thrust}

The isolated engine thrust coefficient $\left(C_{T}\right)$ as a function of advance ratio $(J)$ is investigated at zero angle-of-attack [see Eq. 4]. Figure 8 shows that for the used range of power setpoints, $C_{T}$ is linear with $J$. Reynolds number and tip Mach number can thus safely be disregarded when only using the model at a single free stream velocity. Least squares allows fitting of the model to the data with the following relation:

$$
C_{T}=0.954-0.721 \mathrm{~J}
$$

Within the tested range of advance ratios, i.e. $0.36<J<1.13$, it can be seen that there is little deviation from this linear relationship. This indicates that the flow over the fan blades of the ducted fan is in attached condition. 


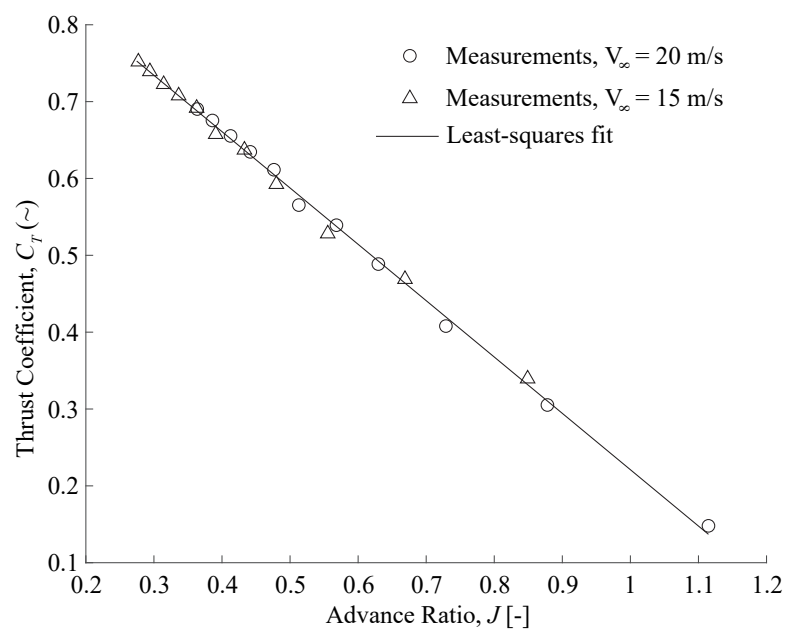

Fig. 8 Propeller thrust coefficient, $C_{T}$, as a function of Advance Ratio, $J$

\section{B. Isolated Wing Lift and Pitching Moment Characteristics}

Figure 9(a) shows the relation between lift and drag for the Flying $\mathrm{V}$ wing. The curve of the model shows a clear kink around $\alpha=10$ degrees. At low incidence angles, the common quadratic relation between $C_{L}$ and $C_{D}$ can be used to describe the aerodynamic performance of the airframe. It is clear though, that while fitting well at the lower incidence angles, the offset at high angle of attack becomes large. At higher lift coefficients, the curve starts to follow the slope of the $C_{L} \tan (\alpha)$ relation between lift and drag more closely. This is the variation expected when the lift force is perpendicular to the wing chord and when no additional leading edge suction force is produced. [22]

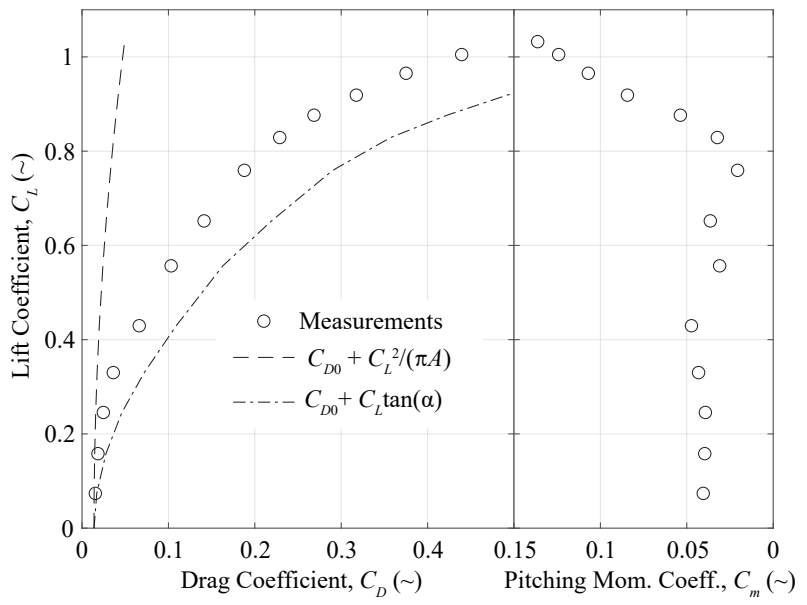

(a) Flying-V model

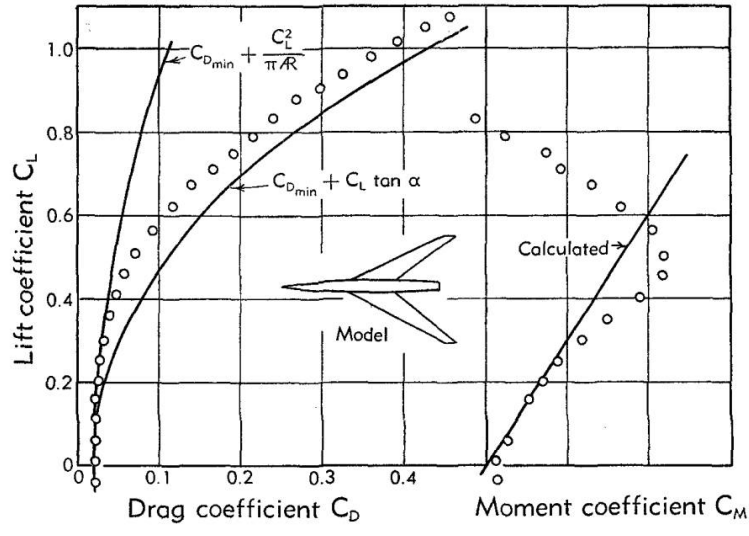

(b) Wing-fuselage model with $60^{\circ}$ sweep angle [22]

\section{Fig. 9 Comparison of lift/drag and pitching moment curves between the Flying $\mathbf{V}$ and a $60^{\circ}$ swept wing model}

Figure 9(b) shows the results obtained by Jones and Cohen for a swept wing model with $60^{\circ}$ sweep, at $R e=8 * 10^{6}$. The similarities between the results of the Flying $\mathrm{V}$ and their results are remarkable. Jones and Cohen explain the departure at approximately $C_{L}=0.3$ from the classical lift drag relation as the onset of flow separation on a swept wing, which leads to a reduced leading edge suction and lift force perpendicular to the chord. [22] They state that this value corresponds to a lift coefficient of 1.2 with respect to the normal component of the stream velocity. Therefore, it is roughly equal to the normal stalling lift coefficient in straight flow. While lift does steadily increase after the "onset of stall," this point could also be seen as the point from which vortex lift starts to play a significant role in the total lift production of the wing. Oil flow measurements by Viet [8] confirm this hypothesis. For the Flying-V subscale wind tunnel model, the angle of incidence corresponding to this lift coefficient is approximately $10^{\circ}$. 


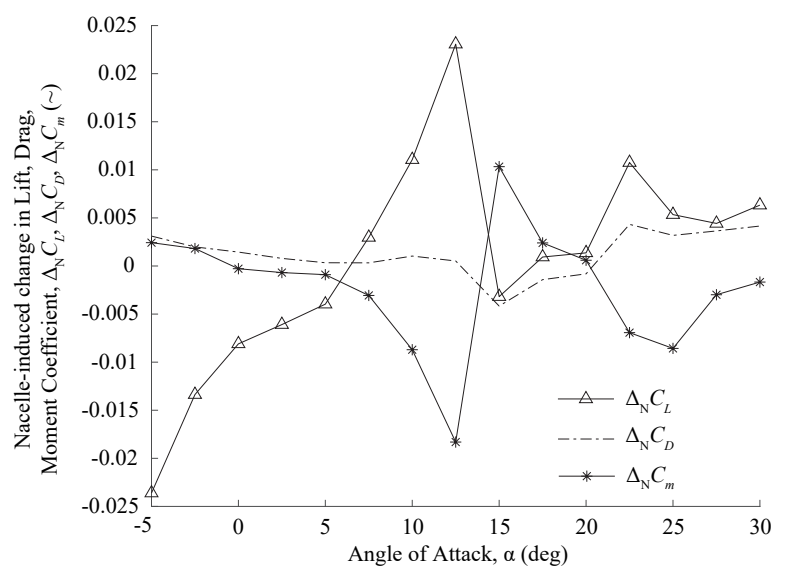

Fig. 10 Installation effect of the through-flow nacelle on lift, drag, and pitching moment. The pitching-moment reference point is at $X=1.36 \mathrm{~m}$.

\section{Effect of Through-Flow Nacelle Installation}

Most of the installation effects of the through-flow nacelle are a direct effect of the interference between the nacelle and wing elements, since the inflow angle of the nacelle is mostly dictated by the wing. Thus, only the installation effects are discussed here for compactness. Figure 10 shows the change in lift coefficient, drag coefficient and pitching moment as a function of angle of attack with respect to clean wing results. For example, $\Delta_{N} C_{L}$ is the change in lift coefficient due to nacelle installation. As can be observed, the nacelle induces a gradually increasing amount of extra lift between $\alpha=5$ and $\alpha=12.5$. For $\alpha \geq 15$, the change in lift is relatively small. The pitching moment coefficient curve is almost a mirror image of the lift curve for over the complete angle-of-attack range. As the nacelle is located behind the pitching-moment reference point (indicated by CG is Fig. 7(a) , the pitching moment contribution is attributed to the change in lift force acting on the nacelle. As the magnitude of the drag force is much smaller (see the dash-dotted line in Fig. 10, its contribution to the pitching moment is relatively small. For $\alpha \geq 15$, the pitching moment and lift contribution of the nacelle become close to zero. Therefore, the nacelle does not have an impact on the pitch-break behavior shown in Figure 9(a).

\section{Effect of Engine Thrust and Nacelle Installation}

The effect of propulsion-system installation is shown in the plots of Figure 11. The propulsion system includes the nacelle and the engine. In each of these graphs, each individual line represents a constant engine rotational speed. Therefore, the advance ration, $J$, is constant for each line. The maximum and minimum advance ratios are marked for reference. In between these lines, the rotational speed of the engine is varied linearly. Figure 11(a) shows that with increasing engine thrust (i.e. lower $J$ ) the lift-curve slope increase and the maximum lift-coefficient also increases. This is attributed to the higher velocity in the inlet streamtube of the engine, which flows over the upper surface of the wing. The net drag-coefficient polars of Figure 11(b) show for which combinations of angle-of-attack and advance ratio positive net thrust is generated. Finally, due position of the thrust vector above the center of gravity, a nose down pitching moment is generated with increasing thrust (Figure 11(c)). However, the thrust contribution is neither linear with $J$, nor with with angle-of-attack. This indicates that there are interference effects at play. It is expected that the greatest velocity increase in the inlet streamtube is experienced close to the inlet lip. Therefore, the thrust-induced low-pressure flow field acts behind the moment reference point and causes an additional nose-down pitching moment. This explains why the change in pitching moment coefficient is higher for thrust variations at low advance ratio. In the following subsection, the interference effects are further expanded.

\section{E. Engine Interference}

The installation effect of the propulsion system can be modeled, to a first degree, as a force vector at the engine location, with a thrust force coefficient located above and behind the moment reference point. However, it is interesting to look at the interference effects of the engine thrust, since these show the differences between the superposition of the measured forces on the isolated components and the measured forces when they are integrated. Using this setup, lift interference 


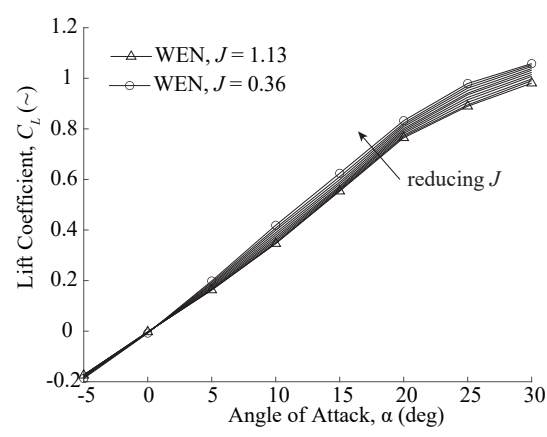

(a) Lift coefficient

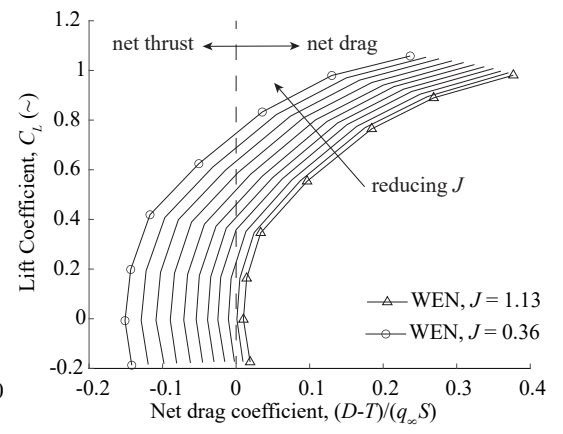

(b) Net drag coefficient

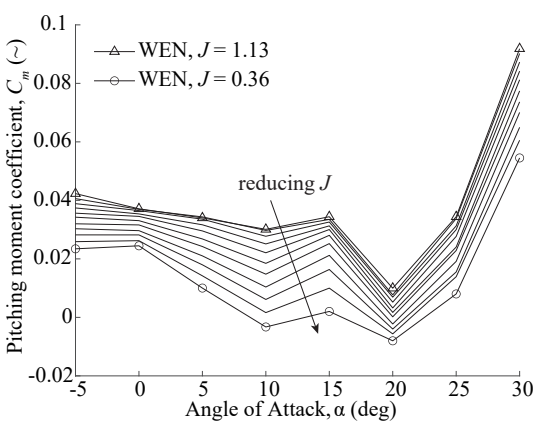

(c) Pitching moment coefficient

Fig. 11 Variation in aerodynamic coefficients with angle-of-attack for various advance ratios. Note, the moment reference point is $X_{C G}=1.36 \mathrm{~m}$.

is estimated with a precision of \pm 40 counts (0.004). Drag and pitching moment are estimated with a precision of \pm 15 counts $(0.0015)$ and \pm 20 counts $(0.002)$, respectively. Figure 12 shows heat maps that quantify the interference effect on the lift, drag and pitching moment coefficient as a function of advance ratio and angle-of-attack. Note that the black dots show the combinations of angle-of-attack and advance ratio for which measurements were taken. Linear interpolation was used in between the measurement points to plot the aerodynamic coefficients. It should be noted that PS indicates the combination of nacelle and engine thrust, while E represents engine thrust only.

From Figure 12(a) it can be observed that at high advance ratio (i.e. low thrust), the interference effects are dominated by the interference effects of the nacelle. This is deduced from the fact that changing the advance ratio brings about very little change in $\delta_{\mathrm{PS}} C_{L}$. However, the interference effect between nacelle and wing has a dependency on the angle-of-attack. While for most angles of attack the nacelle interference reduces the lift coefficient, for $6^{\circ}<\alpha<12^{\circ}$ the lift is somewhat increased. When the advance ratio gets below a value of 0.6 , an effect of the engine thrust becomes visible. Clearly, for $-5^{\circ}<\alpha<10^{\circ}$ and $J=0.36$ the interference lift increases with angle of attack. There are two hypotheses that could explain this behavior. First of all, the aerodynamic interference could result in a change in inflow angle to the nacelle resulting from the presence of the wing. The inflow angle is magnified dependent on the lift coefficient that is produced. The amplification in local angle of attack then results in an amplification of the lift force that is produced by the nacelle. This would be supported by the view that at negative angles of attack, the interference lift is negative, while for positive angles of attack (below $\alpha=10^{\circ}$ ) the interference lift is positive. The second hypothesis is that suction provided by the engine affects the circulation that is produced by the part of the wing. In that case, the streamtube of the engine changes the lift force on the wing similar to how a propeller slipstream effects the wing lift if part of it is positioned in the prop wash. With the current experimental setup, it is not possible to demonstrate, which one of these hypotheses (or a combination thereof) is true. What can be said is that is that at an angle-of-attack of $\alpha>10^{\circ}$ and $J=0.36$, the increase in interference lift with angle-of-attack no longer persists. This is attributed to the formation of vortices over the upper surface of the wing, which have been shown in a previous study by Viet [8]. When vortices appear, it is hypothesized that the inlet streamtube is no longer in the proximity of the wing's upper surface. Therefore, it no longer has an increasing effect on the lift coefficient.

Figure 12(b) shows the change in drag due to interference effects. Red indicates that there is an increase in drag. Here, we do see that the engine thrust has an impact on the interference over a larger range of $J$, although the thrust effect is mostly present for $J<0.75$. Clearly, the interference-drag penalty is mostly angle-of-attack dependent. For $\alpha>7^{\circ}$, all the way up to high angles of attack, there is an increase in perceived drag for the installed engine. A small, but significant decrease is visible in the range between 0 angle of attack and -5 , almost independent of the thrust setting. It is hypothesized that at low (absolute) angles of attack the local dynamic pressure at the engine is lower due to the presence of the wing. This reduces the (friction) drag of the nacelle and hence it benefits from being installed in the vicinity of the wing. However, when the angle-of-attack increases, the upper-surface supervelocities increase and this effect diminishes. Moreover, at a low advance ratio, there is a strong sensitivity of the interference drag due to engine thrust. The maximum interference drag penalty is approximately 60 counts of drag, observed at high thrust setting and $\alpha=10^{\circ}$. To put this in perspective, the maximum interference drag is $16 \%$ of the isolated wing drag in this condition. This might be the result of pressure drag stemming from the stream-tube-induced low-pressure field acting on the wing's 


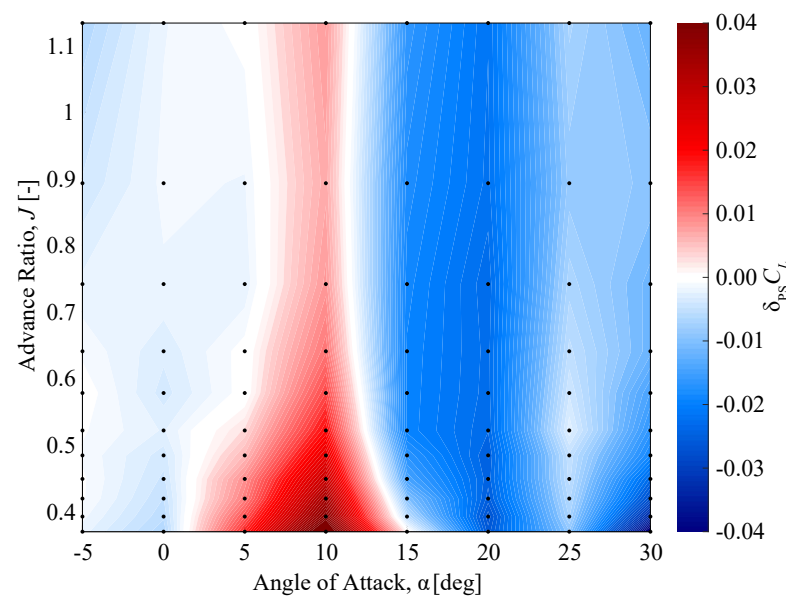

(a) Change in $C_{L}$ due to propulsion system interference

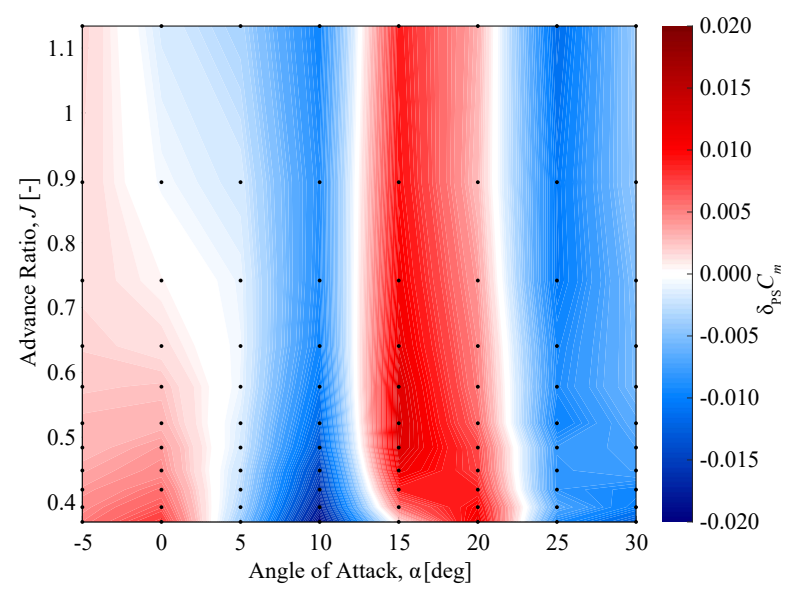

(c) Change in $C_{m}$ due to propulsion system interference

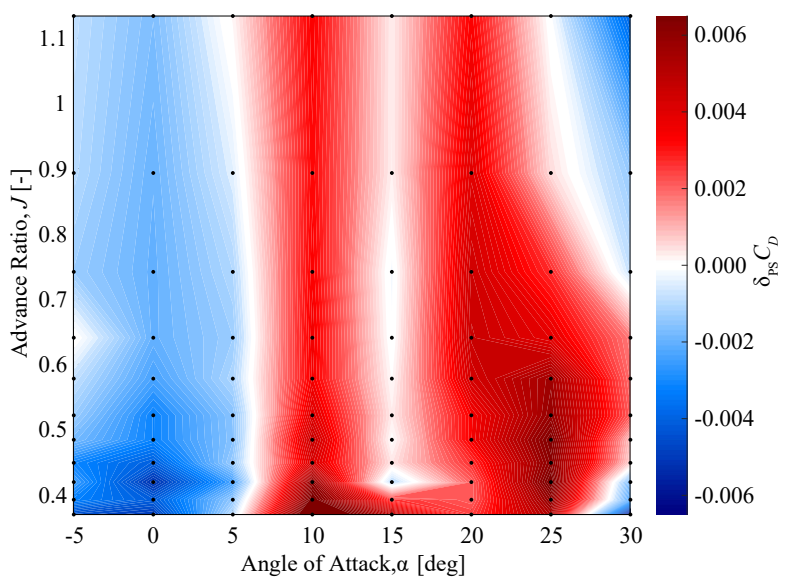

(b) Change in $C_{D}$ due to propulsion system interference

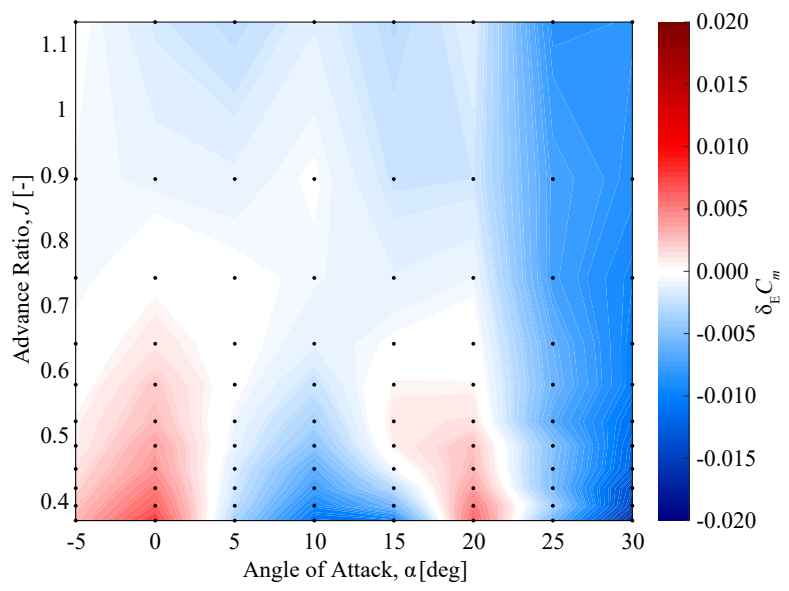

(d) Change in $C_{m}$ due to inlet-streamtube interference

Fig. 12 Interference of the integrated propulsion system at $V_{\infty}=20 \mathrm{~m} / \mathrm{s}$ as a function of angle-of-attack and advance ratio. Pitching moment reference point is at $X=1.36 \mathrm{~m}$.

upper surface.

In terms of pitching moment interference (Figure 12(c)], the engine provides a nose down tendency matching the increase in lift around $10^{\circ}$ angle-of-attack. Between $\alpha=12.5^{\circ}$ and $\alpha=22.5^{\circ}$ an additional nose-up contribution is estimated. Removing the contribution of the nacelle from the engine interference results in the interference between inlet streamtube and wing as shown in Figure 12(d). It should be noted that in terms of coloring the heat map of Figure 12(c) is approximately the inverse of the heatmap of Figure 12(a). This indicates that the interference effect on the pitching-moment coefficient could, to a first degree be approximated as interference lift multiplied by a fixed moment arm. Subsequently, if the heatmap of Fig. 12(d) is compared to the heatmap of Fig. 12(c) it can be seen that the pattern in the graph is similar. This shows that the nonlinear change in pitching moment with angle-of-attack is, to a large-degree, the result of the mutual interference between the inlet streamtube and the wing. When vortices form $\left(\alpha>12^{\circ}\right)$, this interaction changes strongly resulting in a reduction in lift force and corresponding increase in pitching moment.

The photos in Figure 13 show a difference between near-idle and maximum power conditions on the suction side surface at $\alpha=5^{\circ}$. The displacement of the tufts show that the increased suction of the engine "pulls" the surface flow towards the engine inlet. At the relatively low speed of $20 \mathrm{~m} / \mathrm{s}$, the engine's region of influence extends quite far outboard, as highlighted by the red circle. Pressure differences further inboard are harder to distinguish from the tufts, since the general direction of the idle condition surface flow is already pointed towards the engine intake. Still, it can be concluded that the engine suction has a clear effect on the upper surface pressure distribution near the engine intake and 
that drag is increased, both due to increased pressure drag as well as higher friction drag.

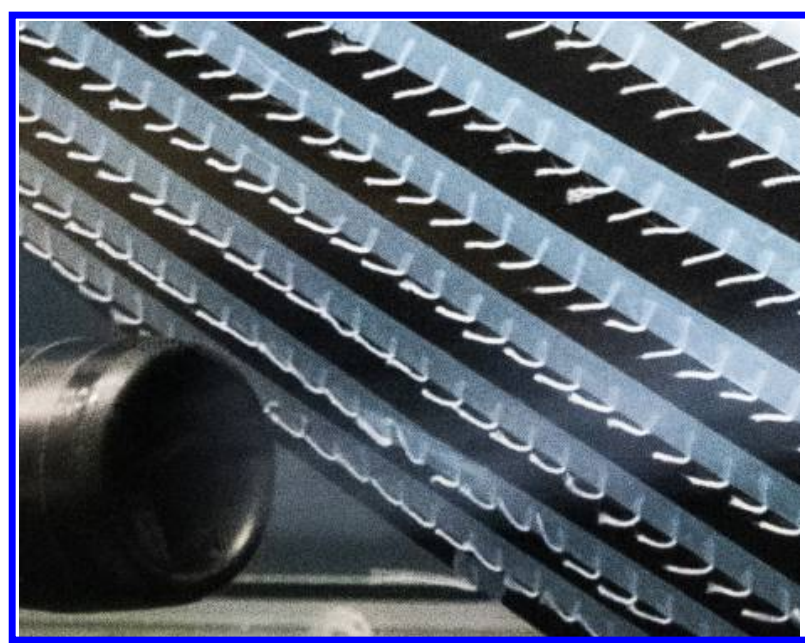

(a) $\alpha=5^{\circ}$, Idle conditions

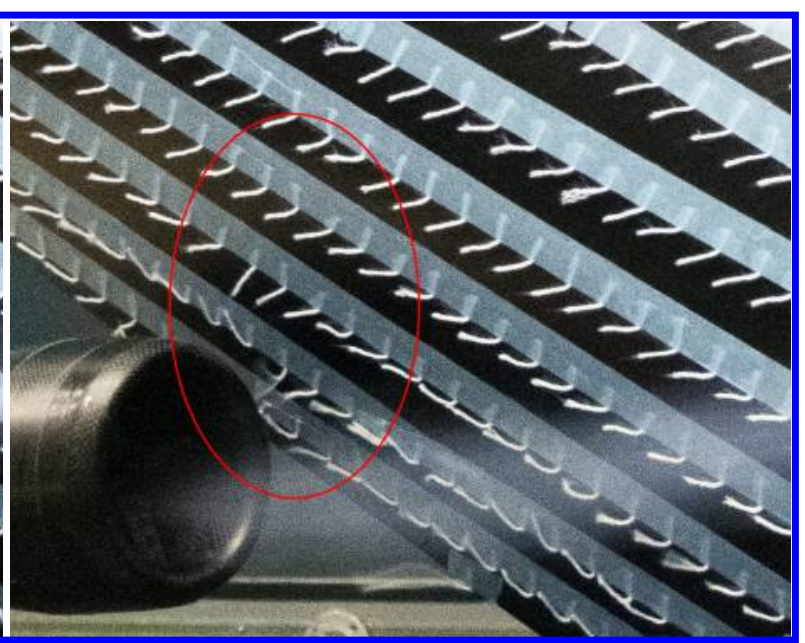

(b) $\alpha=5^{\circ}$, Power On

Fig. 13 Change in surface flow direction due to engine suction

Comparing the effect of engine installation (Figures 11(a) $11(\mathrm{~b})$ and $11(\mathrm{c})$ ) and interference effects (Figures 12(a) 12(b) 12(c)], the following observations can be made. The installation effects of the powered nacelle have a relatively large impact on the pitching moment coefficient. Due to its application point, the thrust force creates a nose down pitching moment. The interference effect between the inlet streamtube and the wing that results from installing the engine causes a nonlinear effect on the pitching-moment coefficient with angle-of-attack that is of the same order of magnitude as the effect of the thrust force on the pitching moment coefficient. The effect of the engine installation on the lift is attributed to the inclination of the thrust vector, with interference effects that are of the same order of magnitude. The power-on interference drag can be substantial, up to 60 counts when $J=0.36$ and $\alpha=10^{\circ}$. This is attributed to the increase in pressure and friction drag on the wing resulting from the engine-inlet streamtube.

\section{Conclusion}

The effect of engine installation on the aerodynamic characteristics of the Flying V is investigated experimentally, using a $4.6 \%$ scale half model in a low-speed wind tunnel at a wind speed of $20 \mathrm{~m} / \mathrm{s}$. It is shown that the installation of the engine results a small increase lift-curve slope with increasing thrust coefficient and corresponding decrease in fan advance ratio. Engine installation causes an additional nose-down pitching moment coefficient with a maximum value -0.04 at the smallest fan advance ratio of $J=0.36$ and an angle-of-attack of 10 degrees. Also at $J=0.36$, there is a growing interference-drag penalty for angles-of-attack beyond 5 degrees. A maximum interference drag penalty of 60 counts at $10^{\circ}$ is recorded. At incidence angles lower than $5^{\circ}$, engine operation results in a favorable contribution to the uninstalled thrust with a maximum negative interference drag of 20 counts. An increased nose-down pitching moment is observed due to engine-thrust interference between $-5^{\circ}$ and $12.5^{\circ}$ angle of attack with a maximum contribution of -0.02. An increase in nose-up pitching moment from $12.5^{\circ}$ to $22.5^{\circ}$ is observed with a maximum of +0.02 . Comparing installation and interference effects, it is remarked that lift interference and pitching moment interference are measured to be of the same order of magnitude as the installation effects due to thrust. Mutual interference effects between engine and wing can therefore not be neglected for the Flying-V. However, further research should demonstrate how the local pressure distribution is altered when the engine is added to the wing in order to reveal the cause of the measured interference on the force and moment coefficients presented in this study.

\section{References}

-[1] Torenbeek, E., Advanced Aircraft Design, John Wiley and Sons, Ltd, Chichester, UK, 2013. https://doi.org/10.1002/ 9781118568101 
[2] Martinez-Val, R., "Flying Wings. A New Paradigm for Civil Aviation?" Acta Polytechnica, Vol. 47, No. 1, 2007. https://doi.org/10.14311/914.

[3] Benad, J., "The Flying V - A New Aircraft Configuration for Commercial Passenger Transport," Deutscher Luft- und Raumfahrtkongress, 2015, pp. 1-8. https://doi.org/http://dx.doi.org/10.1016/S0140-6736(17)32758-7

- [4] Faggiano, F., Vos, R., Baan, M., and Van Dijk, R., “Aerodynamic design of a flying V aircraft," 17th AIAA Aviation Technology, Integration, and Operations Conference, 2017, 2017. https://doi.org/10.2514/6.2017-3589

[5] Van Gorcum, J. J., "Ready For Take-off: Scaled Flight Testing,” Msc thesis, Delft University of Technology, 2017.

[6] Pettersson, K., and Rizzi, A., “Aerodynamic scaling to free flight conditions: Past and present," Progress in Aerospace Sciences, Vol. 44, No. 4, 2008, pp. 295-313. https://doi.org/10.1016/j.paerosci.2008.03.002

- [7] Palermo, M., "Experimental Aerodynamic Analysis of a 4.6\%-Scale Flying-V Subsonic Transport," Proceedings of AIAA Scitech 2020 Forum, Orlando, FL, 2020.

[8] Viet, R. A., "Analysis of the flight characteristics of a highly swept cranked flying wing by means of an experimental test," Msc thesis, Delft University of Technology, 2019.

[9] Dickey, E. D., Princen, N. H., Bonet, J. T., and Ige, G. K., "Wind tunnel model design and fabrication of a 5.75\% scale blendedwing-body twin jet configuration," 54th AIAA Aerospace Sciences Meeting, 2016, pp. 1-24. https://doi.org/10.2514/6.2016-0008

[10] Vicroy, D. D., Dickey, E., Princen, N., and Beyar, M. D., "Overview of Low-speed Aerodynamic Tests on a 5.75\% Scale Blended-Wing-Body Twin Jet Configuration,” 54th AIAA Aerospace Sciences Meeting, 2016.

-[11] Hoheisel, H., "Aerodynamic Aspects of Engine-Aircraft Integration of Transport Aircraft," Aerospace Science and Technology, Vol. 1, No. 7, 1997, pp. 475-487. https://doi.org/10.1016/S1270-9638(97)90009-2.

-[12] Hoheisel, H., Frhr, H., and Geyr, V., "The influence of engine thrust behaviour on the aerodynamics of engine airframe integration,” CEAS Aeronautical Journal, Vol. 3, No. 1, 2012, pp. 79-92. https://doi.org/10.1007/s13272-012-0044-x

- [13] Kooi, J. W., de Haij, L., and Hegen, G. H., "Engine simulation with turbofan powered simulators in the german-dutch wind tunnels," 22nd AIAA Aerodynamic Measurement Technology and Ground Testing Conference, 2002, pp. 1-12. https://doi.org/10.2514/6.2002-2919

[14] Hegen, G. H., and R, K., "Experiences with ultra-high bypass simulators from calibration and isolated engine testing," Tech. Rep. NLR-TP-1996-193, National Aerospace Laboratory NLR, 1996.

-[15] Harris, A. E., and Paliwal, K. C., "Civil Turbofan Propulsion System Integration Studies Using Powered Testing Techniques at ARA, Bedford,” 13th Aerodynamic Testing Conference, 1984, pp. 74-98. https://doi.org/10.2514/6.1984-593

-[16] Burgsmüller, W., and Hoheisel, H., "ENIFAIR — EU research into engine integration on future transport aircraft," Air \& Space Europe, Vol. 2, No. 2, 2000, pp. 81-85. https://doi.org/10.1016/s1290-0958(00)80047-7.

[17] Campomanes, C. S., "External Flow Effects in the Engine/Airframe Integration Testing Technique A new Thrust/Drag Bookkeeping Approach at the German-Dutch Wind Tunnels,” Msc thesis, Delft University of Technology, 2017.

[18] Lv, P., Rao, A. G., Ragni, D., and Veldhuis, L., "Performance analysis of wake and boundary-layer ingestion for aircraft design," Journal of Aircraft, Vol. 53, No. 5, 2016, pp. 1517-1526. https://doi.org/10.2514/1.C033395

-[19] Ruiz Garcia, A., and Vos, R., "Aerodynamic Model Identification of the Flying V from Wind Tunnel Data," Proceedings of the AIAA AVIATION 2020 FORUM, AIAA paper 2020-2739, 2020. https://doi.org/10.2514/6.2020-2739

[20] Kriegsman, R., and Reede, B., “Aerospace Engineering: The Open Jet Facility,” $2016 . \quad$ URL http: //www.lr.tudelft.nl/nl/organisatie/afdelingen/aerodynamics-wind-energy-flight-performance-and-propulsion/facilities/windtunnel-lab/open-jet-facility-hsl/

[21] Trancossi, M., and Madonia, M., "The efficiency of an electric turbofan vs. inlet area: A simple mathematical model and CFD simulations,” SAE Technical Papers, Vol. 10, No. November 2016, 2012. https://doi.org/10.4271/2012-01-2217

[22] Jones, R. T., and Cohen, D., High Speed Wing Theory, Princeton University Press, Princeton, NJ, 1960. 